\title{
Neurocognitive abilities in individuals with Down syndrome-a narrative review
}

\author{
Sidra Kaleem Jafri ${ }^{1 \oplus}$, Karen Elizabeth Harman ${ }^{2 \odot}$ \\ ${ }^{1}$ Department of Pediatrics and Child Health, Aga Khan University, Karachi, Pakistan; ${ }^{2}$ Division of Developmental Pediatrics, \\ Department of Pediatrics, McMaster University, Canada.
}

\begin{abstract}
Down syndrome (DS), or trisomy 21, is the most common genetic syndrome associated with intellectual disability. Despite the variability in expression, there is a distinct developmental phenotype characterized by deficits in learning/memory, executive functions, and language skills accompanying the psychomotor delay. The severity of intellectual impairment has the dominant effect on functioning, other influences such as parental and societal attitudes, supports available and social opportunities also play a role in the attainment of skills.
\end{abstract}

Key words: Down syndrome, cognition, learning.

Down syndrome (DS), or trisomy 21 , is a common disorder associated with several complex clinical phenotypes. DS is estimated to occur in approximately 1 per $650-1000$ live births. ${ }^{1}$ A recent study from the Unites States of America showed a decrease in the prevalence owing to DS related elective terminations. ${ }^{2}$ The features of DS were identified 150 years ago by Sir John Langdon Down who published his findings in London Hospital Clinical Lectures and Reports in 1866. After 66 years, P. J. Waardenburg suggested that DS was caused by a chromosomal aberration due to nondisjunction. ${ }^{3}$ After almost a century later, an extra copy of chromosome 21 was identified as the etiology. In the $20^{\text {th }}$ century, almost all individuals with DS were separated from their families and institutionalized. They were also denied medical support which culminated in increased mortality in children with DS. ${ }^{5}$ However, the advances in the medical and surgical treatment have led to improved life expectancies such as specialized surgical procedures of the congenital cardiac diseases, management of malignancies and

\footnotetext{
Sidra Kaleem Jafri

sidrakaleemjafri@gmail.com
}

Received 17th March 2020, revised 11th June 2020, accepted 7th July 2020. endocrinopathies. ${ }^{6}$ There has also been a change in the social circumstances for individuals with DS, as most are being reared at home. ${ }^{7}$

DS is diagnosed through karyotyping along with the phenotypic presentation. Maternally derived additional copy of an entire chromosome 21 due to non-disjunction is the most common cause of DS occurring in approximately 9093\% of the cases. ${ }^{5}$ Translocation is the other pathological mechanism which causes DS in $\sim 2-$ $4 \%$ of the cases. Mosaicism is found in $\sim 1.3-5 \%$ of cases. ${ }^{8}$ In $95 \%$ of the children, the condition is sporadic. ${ }^{9}$

The prenatal screening strategies have been developed ranging from amniocentesis to less invasive tests for different trimesters that incorporate various blood tests, nuchal translucency via ultrasonography. ${ }^{9}$

Substantial research has been carried out in the past several decades to unravel the molecular genetics of DS. ${ }^{10}$ Although, some studies have suggested that duplication of an extended region on chromosome 21 (HSA21) is associated with DS features but it is yet to be established. It is also hypothesized that there is a critical region involved, ${ }^{11}$ the DS consensus region that is responsible for severe DS phenotype. ${ }^{10}$ 
DS is the most common known genetic cause of intellectual and developmental disabilities. ${ }^{12}$ Although there is a global involvement encompassing motor, language, cognitive, selfcare and personal-social dimensions ${ }^{13}$, there is a disproportionate impairment in certain cognitive domains such as language and memory in comparison to other intellectual disabilities resulting in a characteristic neurocognitive phenotype. ${ }^{6}$ However, there is heterogeneity amongst individuals in the cognitive abilities and skills phenotype due to genetics, cellular, neural, behavioral and environmental factors. ${ }^{8}$ Research studies have shown that there is anomalous functional neural connectivity as compared to individuals with similar intellectual disabilities. ${ }^{14}$ Also, mitochondrial dysfunction has been studied in correlation with the pathogenesis of DS and there is evidence to show increased oxidative stress in DS cells. ${ }^{15}$ However, it is not known how oxidative stress causes clinical symptoms and there is a knowledge gap in the understanding of the molecular events leading to intellectual disability. ${ }^{16}$

\section{Motor skills}

There is a need for proficient motor skills in individuals with DS to perform day to day tasks. ${ }^{17}$ Children with DS demonstrate challenges in terms of increased risk of motor delay and motor coordination capabilities which occur due to neuroanatomical and physiological changes because of muscle hypotonia, lax joints and slower reaction times causing alterations in postural control and muscle synergy. ${ }^{13,18}$ This delay in motor skills may also hinder the child from the essential sensory stimulation that is needed for other aspects of learning. ${ }^{19}$

The gap in motor development emerges around 4 months of age and becomes more apparent as the age advances. Dissimilarities in the postural reactions have also been observed while comparing to neurotypical infants. ${ }^{20}$ This happens as expectations for more coordinated motor tasks increase especially for skills requiring high levels of muscle co-activation against gravity. The sequence of attaining motor milestones is similar but qualitatively different which probably results from the compensatory mechanism. There is a wide range in the acquisition of motor milestones such that walking can be attained between 15 and 74 months while for the neurotypical children it is earlier than 18 months. ${ }^{21}$ The percentage of children who were able to walk by 2 years of age has been reported between $25 \%$ to $44 \%$, and by 3 years $78 \%$ to $82 .{ }^{22}$

There is a paucity of literature on the fine motor development in DS. It is heterogeneous and like gross motor skills has a broad range of acquisition. The achievement of early fine motor skills and writing skills is around the same age range as the typical children. However, with the increasing complexity of tasks, the difference increases between the children with DS and their typical peers. ${ }^{23}$

An interesting phenomenon in enhancing motor capabilities in individuals with DS is an improvement in tasks with practice as unfamiliarity of the motor tasks results in even worse motor coordination. ${ }^{24}$ The existing body of literature, although limited, suggests that neuromuscular training which is characterized by stimuli provided by physical activities aims to enhance a myriad of neuromuscular components including muscular strength, physical coordination, and functional movements may be employed to promote general and maximal muscular strength development in children and youth with DS. However, there is a small impact on functional mobility performance owing to limitations in executive functioning. ${ }^{25}$ Thus, rehabilitation contributes to the improvement of motor skills and ultimately the quality of life. ${ }^{26}$

Given this literature, general pediatricians may wish to consider co-morbid neurologic or developmental diagnosis if a child with DS presents with hypertonia, have asymmetric neurological findings or are significantly more motor delayed than most children with DS (for example not walking by 60-72 months). 


\section{Adaptive functioning}

Adaptive behavior is essential to perform day to day activity independently and is comprised of conceptual, social, and practical adaptive skills. ${ }^{27}$ The understanding of the adaptive behavior profile of DS is evolving. ${ }^{28}$ So far, the adaptive behavior profile in DS is characterized by strengths in socialization and self- help ${ }^{29}$ with difficulties in motor and communication skills. ${ }^{30}$

Progression in adaptive functioning is particularly seen in early childhood up to the age of 6 years; while in children and adolescents the gains in adaptive skills are not strongly correlated with age. ${ }^{31}$

Children with DS find it difficult to keep up with their typical peers in adaptive skills and deceleration is observed across all ages. ${ }^{30}$ The domains continue to grow at a slower pace than typically developing children. Also, there is great variability in the attainment of skills in children with DS as compared to their typical peers such that adaptive scores are close together in neurotypical children in relation to their chronological age; while the scores have a larger spread in children with DS. ${ }^{32}$

\section{Speech and language (Communication)}

There is a characteristic profile of communication with strengths and challenges in individuals with DS. ${ }^{33}$ Children with DS typically manifest significant delays in language development. ${ }^{34}$ There are deficits in both receptive and expressive language skills which are more pronounced than cognitive development. ${ }^{35}$ In general, expressive language is more affected than receptive language and/or language comprehension. ${ }^{36}$ Hearing loss and anatomical and functional differences in the oro-motor apparatus have been associated with speech delay. ${ }^{37}$

Craniofacial differences including small oral cavity and narrow, vaulted palate, as well as hypotonia, contribute to the articulatory performance. $^{38}$
The motor speech difficulties have historically included Childhood Apraxia of Speech (CAS) and Childhood Dysarthria. One can have either or both. ${ }^{38}$

The development of oral language is a complex process which requires cognitive, perceptual and language skills that begin to form in the prelinguistic stage ${ }^{39}$ Similar to typical children, children with DS use gestures and vocalizations in the prelinguistic stage. Children with DS show better performance using gestural communication than is expected for their developmental age thus placing them in "gestural advantage". ${ }^{40}$ Delays in certain aspects of prelinguistic vocalizations especially canonical babbling (repeating consonants and vowels) ${ }^{41,42}$ followed by delays to attain single words speech have been reported in the literature. ${ }^{37}$ There is a range in the acquisition of the first words such that for some children the first words have emerged at around 9 months while for others they didn't come until 7 years of chronological age. ${ }^{43}$

The issues revolve around language production, syntax (sentence structure) and poor speech intelligibility. ${ }^{44,45}$ Pragmatics (social use of language) is an area of relative strength for children with DS. ${ }^{46}$

Studies have suggested that early linguistic stimulation employing speech and language interventions specially designed for children with DS individualized with each child's characteristics can potentiate language development. $^{39}$

Therefore, from the literature, pediatricians may consider comorbid developmental diagnosis if a child with DS has more impairments in the pragmatics than compared to their overall developmental level or if the clarity of the expressive communication is significantly unintelligible after short sentence utterances have been achieved.

\section{Social-emotional/ behavioral development}

Socialization is the strongest developmental 
domain in children with DS. ${ }^{47}$ It has been supported by literature that children with DS with the same level of developmental delay as children without DS demonstrated better socialization skills. ${ }^{30}$ Also, different dimensions of social functioning such as social orientation, social engagement, and pro-social responsiveness are equally strong. ${ }^{48,49}$

Children with DS have been characterized by decreased emotional expression and environmental response. ${ }^{50,51}$ Studies have shown that infants with DS displayed less intense emotions and increased latency to distress as compared to developmentally matched infants. ${ }^{52}$

Research on the recognition of emotional expressions by children with DS has been a work in progress. ${ }^{53}$ Previous literature suggested that they have a better understanding of understanding emotions as expressed by facial expression as compared to other forms of intellectual disabilities. ${ }^{54}$ Later studies looking into emotional processing in children with DS concluded that there were emotional perception deficits. ${ }^{55}$

A child with DS has been stereotyped to be affectionate, charming and friendly. ${ }^{48}$ Thus, the co-occurrence of Autism Spectrum Disorder (ASD) with DS was considered to be a rare phenomenon in the past. However, recent research estimates have shown the prevalence of co-occurring ASD to be 5 to $18 \%$ in children with DS. ${ }^{56-58}$ The published literature has not shown comprehensive or "gold standard" diagnostic assessments for diagnosing ASD in children with DS. ${ }^{59}$ However, screening tools like Social communication questionnaire (SCQ) and Modified Checklist for Autism in Toddlers $(\mathrm{M}-\mathrm{CHAT})^{56}$ have been used followed by Autism Diagnostic Interview-Revised (ADIR) and Autism Diagnostic Observation Schedule (ADOS). ${ }^{60}$ Keeping in view that many of the symptoms that constitute the autism screening checklists are also present in intellectual disabilities, this may result in increased sensitivity with decreasing specificity ${ }^{61}$ A developmental approach to diagnose ASD has been recommended by various authors in children with intellectual disabilities where to diagnose an individual with ASD there should be significantly more impairment in social or communication domain than the overall intellectual capabilities. ${ }^{62}$

Several studies have contributed in creating the behavioral profile of children with DS with a dual diagnosis of ASD which includes increased behavioral disturbance, increased repetitive and stereotypical behavior, poorer social, language and adaptive skills and greater regression. ${ }^{56}$ Another study demonstrated that individuals with a dual diagnosis of ASD-DS were less withdrawn than with idiopathic ASD. ${ }^{57}$

Maladaptive behaviors in DS occur in varying intensities across the lifespan. About onethird of individuals with DS have behavior challenges. ${ }^{63}$ Behavior problems like inattention, stubbornness, non-compliance social- withdrawal and obsessive-compulsive behaviors have also been established in the profile. $^{64,65}$ In children with DS who have behavioral problems, vocabulary has been found to be a major contributor. ${ }^{66}$ More externalizing behaviors have been observed in children with DS as compared to adolescents while both adolescents and adults have shown more propensity towards internalizing behaviors. $^{48}$

Attention Deficit Hyperactivity Disorder (ADHD) has been reported in 9- 34\% of children with DS. ${ }^{67,68}$ Similar to ASD, making a dual-diagnosis of ADHD in a DS child is more difficult because some signs of ADHD and other comorbid disorders may be attributed to the child's intellectual disability. ${ }^{69}$ Hyperactivityimpulsivity-inattention have been regarded as parts of the typical DS behavioral phenotype thus increasing the dilemma of diagnosing and treating ADHD in them even further. ${ }^{70}$ The diagnosisis clinical and there are nostandardized tests available to detect ADHD in children with DS. However, a neurodevelopmental assessment using clinical observation and 
general rating tools like Aberrant Behavior Checklist (ABC), Child Behavior Checklists (CBCL), Conner's rating scale and/or Strengths and Difficulties Questionnaire (SDQ) etc. could be considered in all children with DS during clinical visits when there is a concern about inattention or impulsivity. ${ }^{69}$ This may facilitate in implementing therapeutic interventions (both pharmacologic and behavioral) which decrease symptoms of hyperactivity and irritability. ${ }^{70}$

\section{Cognition}

The neurocognitive profile of DS is characterized by psychomotor delay with significant deficits in learning, memory, executive functions, and language abilities that define the intellectual disability. ${ }^{21}$

The intelligence quotient (IQ) in individuals with DS vary widely from below 20 to at least an IQ of 69 depending on the age, environment and the genotype. ${ }^{71} \mathrm{~A}$ progressive declining trend has been demonstrated in individuals across childhood ranging between 60-70s in the preschool age group with a subsequent decrease to between 40-50s in kindergarten and further decline dropping to between 30-40 in school-aged children. ${ }^{72}$ This declining cognitive growth rate correlates with declines observed in the rate of development of functional skills during childhood in DS. ${ }^{73}$ However, the psychometric testing available does not account for the wide range of challenges experienced by this population. ${ }^{16}$

Few cognitive differences have been observed in infants with DS from neurotypical controls on standardized tests which may be due to a probable lack of sensitivity to detect them but, with increasing age, the gap becomes more obvious as the rate of intellectual development in DS slows considerably. ${ }^{8}$ Deficits in verbal information processing are the most apparent which is also associated with verbal working memory have been reported in the literature which was historically known to be associated with the deficits in the auditory short-term memory. ${ }^{74}$
Executive functioning has also been found to be impaired in individuals with DS. Impairments in fluency, cognitive flexibility (shifting), planning, and inhibition were found in youth and middle-aged adults with DS when compared with adults with other developmental disabilities (DD) ${ }^{75}$ Interestingly, there is also heterogeneity in performance even after acquiring skill with rigorous training. This is supported by studies that tested and retested children with DS and found the tasks which were successfully done during one test could not be replicated in the other instance. These deficits in memory can be explained by impairment in hippocampal function which is linked to the explicit memory. ${ }^{76}$

In contrast, visuospatial functioning and social relatedness are areas of relative strength. ${ }^{77,78}$

\section{Academics}

Academic skills in individuals with DS have garnered a lot of attention in the last few decades. From the perspective of quality of life, literacy, the ability of reading and writing as well as numeracy, the concept of the number are important in day to day life and facilitate the vocational opportunities as well as chances of independent living in individuals with DS.79,80

There is a spectrum of attainment of literacy skills in children with DS. When compared with mental age-matched children, the language was a stronger predictor of reading ability in contrast to cognition in the group with DS. There is evidence to suggest that there are strengths in word identification, possibly secondary to relative strengths in visual processing. However, there are challenges in verbal processing skills that lead to deficits in word attack skills. ${ }^{79}$

Individuals with DS can attain simple skills in numeracy but a study suggested that unlike reading this cannot be retained into adolescence and adulthood. ${ }^{81}$ Research has also shown that children with DS can improve on these skills if appropriate strategies are used that employ 
their stronger visual learning skills. Learning Numeracy has been suggested to be associated with real practical scenarios with concrete materials or computers. ${ }^{82}$

The learning process is said to be hindered by deficits in the working memory and executive functioning. ${ }^{83,84}$ Another study that looked at the predictors of academic attainment elucidated that severity of learning disability, child's ability to sustain attention, mainstream education, mothers using a practical approach to problemsolving and fathers' feelings of having control over some parts of life positively impacted the achievement. ${ }^{85}$ Children whose mothers were more supportive of their autonomy showed more persistence in performing challenging tasks. Interestingly, the relative social strength hinders collaborative learning as students with DS use avoidance and refusing tactics to save themselves from performing challenging tasks. $^{86,87}$ Researchers also observed higher levels of off-task behavior when children with DS were matched for mental age. ${ }^{70}$ Deficits in goal-directed behavior have also been reported in the literature. ${ }^{88}$

Educational policies that emphasized inclusion and teaching academic skills, resulted in better attainment of skills and higher expectations of teachers. Also, a report on the practice of including children with DS in regular classrooms in England showed a difference in the phenotypic profile in older children and adolescents with DS. ${ }^{89}$ They noted that children with DS attending school in special classrooms showed strength in socialization and activities of daily living while having marked deficits in adaptive communication. ${ }^{76}$ In contrast, children who were in inclusive classrooms, these marked deficits were not demonstrated, and these children had much higher scores on speech, language, and academic skills. The learning targets, however, were individualized with additional in-class and some outside instruction when necessary. ${ }^{89}$

\section{Take-home points}

- The neurocognitive profile of DS is characterized by psychomotor delay and a generalized with significant deficits in learning, memory, executive functions, and language abilities that define the intellectual disability.

- Children with DS are typically delayed in all areas of development throughout their lives.

- The gap in the developmental skills widens during school-age childhood and adolescence compared to their same-age peers widens due to the slower pace of skill acquisition.

- Language is a stronger predictor of reading ability in contrast to cognition in the group with DS.

- The use of the combination of visual and phonological strategies in preschool children to augment the long-term learning has been supported by the literature.

\section{REFERENCES}

1. Baird PA, Sadovnick AD. Life expectancy in Down syndrome. J Pediatr 1987; 110: 849-854.

2. de Graaf G, Buckley F, Dever J, Skotko BG. Estimation of live birth and population prevalence of Down syndrome in nine U.S. states. Am J Med Genet A 2017; 173A: 2710-2719.

3. Jay V. Dr John Langdon Down. Arch Pathol Lab Med 1999; 123: 102.

4. Lejeune J, Gautier M, Turpin R.Study of somatic chromosomes from 9 mongoloid children. C R Hebd Seances Acad Sci 1959; 248: 1721-1722.

5. Ganguly BB, Kadam NN. Down syndrome: from the age of characterization to the era of curative approach. Nucleus 2017; 60: 197-208.

6. HartSJ, VisootsakJ, TamburriP, etal.Pharmacological interventions to improve cognition and adaptive functioning in Down syndrome: strides to date. Am J Med Genet A 2017; 173A: 3029-3041.

7. Melyn MA, White DT. Mental and developmental milestones of noninstitutionalized Down's syndrome children. Pediatrics 1973; 52: 542-545. 
8. Karmiloff-Smith A, Al-Janabi T, D'Souza H, et al. The importance of understanding individual differences in Down syndrome. F1000Res 2016; 5: 389.

9. Bull MJ, Committee on Genetics. Health supervision for children with Down syndrome. Pediatrics 2011; 128: 393-406.

10. Korbel JO, Tirosh-Wagner T, Urban AE, et al. The genetic architecture of Down syndrome phenotypes revealed by high-resolution analysis of human segmental trisomies. Proc Natl Acad Sci USA 2009; 106: 12031-12036.

11. Rahmani Z, Blouin JL, Creau-Goldberg N, et al. Down syndrome critical region around D21S55 on proximal 21q22.3. Am J Med Genet Suppl 1990; 7: 98-103.

12. Bittles AH, Bower C, Hussain R, Glasson EJ. The four ages of Down syndrome. Eur J Public Health 2007; 17: 221-225.

13. Ferreira- Vasques AT, Lamônica DA. Motor, linguistic, personal and social aspects of children with Down syndrome. J Appl Oral Sci 2015; 23: 424430.

14. Grieco J, Pulsifer M, Seligsohn K, Skotko B, Schwartz A. Down syndrome: cognitive and behavioral functioning across the lifespan. Am J Med Genet C Semin Med Genet 2015; 169C: 135-149.

15. Valenti D, de Bari L, De Filippis B, Henrion-Caude A, Vacca RA. Mitochondrial dysfunction as a central actor in intellectual disability-related diseases: an overview of Down syndrome, autism, Fragile $X$ and Rett syndrome. Neurosci Biobehav Rev 2014; 46: 202-217.

16. de Sola S, de la Torre R, Sánchez-Benavides G, et al; TESDAD Study Group. A new cognitive evaluation battery for Down syndrome and its relevance for clinical trials. Front Psychol 2015; 6: 708.

17. Jobling A. Motor development in school-aged children with Down syndrome: a longitudinal perspective. Intl J Disabil Dev Educ 1998; 45: 283293.

18. Cimolin V, Galli M, Grugni G, et al. Gait patterns in Prader-Willi and Down syndrome patients. J Neuroeng Rehabil 2010; 7: 28.

19. Clearfield MW. The role of crawling and walking experience in infant spatial memory. J Exp Child Psychol 2004; 89: 214-241.

20. Haley SM. Sequence of development of postural reactions by infants with Down syndrome. Dev Med Child Neurol 1987; 29: 674-679.

21. VicariS. Motor development and neuropsychological patterns in persons with Down syndrome. Behav Genet 2006; 36: 355-364.
22. Palisano RJ, Walter SD, Russell DJ, et al. Gross motor function of children with Down syndrome: creation of motor growth curves. Arch Phys Med Rehabil 2001; 82: 494-500.

23. Frank K, Esbensen AJ. Fine motor and self-care milestones for individuals with Down syndrome using a Retrospective Chart Review. J Intellect Disabil Res 2015; 59: 719-729.

24. Latash ML. Learning motor synergies by persons with Down syndrome. J Intellect Disabil Res 2007; 51(Pt 12): 962-971.

25. Sugimoto D, Bowen SL, Meehan WP 3rd, Stracciolini A. Effects of neuromuscular training on children and young adults with Down syndrome: systematic review and meta-analysis. Res Dev Disabil 2016; $55: 197-206$

26. Memisevic H, Macak A. Fine motor skills in children with Down syndrome. Spec Edukac i Rehabil (Beograd) 2014; 13: 365-377.

27. Tassé MJ, Luckasson R, Schalock RL. The relation between intellectual functioning and adaptive behavior in the diagnosis of intellectual disability. Intellect Dev Disabil 2016; 54: 381-390.

28. Dykens EM, Hodapp RM, Evans DW. Profiles and development of adaptive behavior in children with Down syndrome. Downs Syndr Res Pract 2006; 9: 45-50.

29. Will EA, Caravella KE, Hahn LJ, Fidler DJ, Roberts JE. Adaptive behavior in infants and toddlers with Down syndrome and fragile $X$ syndrome. Am J Med Genet B Neuropsychiatr Genet 2018; 177: 358-368.

30. Dressler A, Perelli V, Feucht M, Bargagna S Adaptive behaviour in Down syndrome: a crosssectional study from childhood to adulthood. Wien Klin Wochenschr 2010; 122: 673-680.

31. van Duijn G, Dijkxhoorn Y, Scholte EM, van Berckelaer-Onnes IA. The development of adaptive skills in young people with Down syndrome. J Intellect Disabil Res 2010; 54: 943-954.

32. Hauser-Cram P, Warfield ME, Shonkoff JP, Krauss MW, Upshur CC, Sayer A. Family influences on adaptive development in young children with Down syndrome. Child Dev 1999; 70: 979-989.

33. Brown FR 3rd, Greer MK, Aylward EH, Hunt HH Intellectual and adaptive functioning in individuals with Down syndrome in relation to age and environmental placement. Pediatrics 1990; 85(3 Pt 2): $450-452$

34. Martin GE, Klusek J, Estigarribia B, Roberts JE. Language characteristics of individuals with Down syndrome. Top Lang Disord 2009; 29: 112-132. 
35. Cleland J, Wood S, Hardcastle W, Wishart J, Timmins C. Relationship between speech, oromotor, language and cognitive abilities in children with Down's syndrome. Int J Lang Commun Disord 2010; 45: 83-95.

36. Mason-Apps E, Stojanovik V, Houston-Price C, Buckley S. Longitudinal predictors of early language in infants with Down syndrome: a preliminary study. Res Dev Disabil 2018; 81: 37-51.

37. Rondal JA, Comblain A. Language in adults with Down syndrome. Downs Syndr Res Pract 1996; 4: 3-14.

38. Roberts JE, Price J, Malkin C. Language and communication development in Down syndrome. Ment Retard Dev Disabil Res Rev 2007; 13: 26-35.

39. Rupela V, Velleman SL, Andrianopoulos MV. Motor speech skills in children with Down syndrome: a descriptive study. Int J Speech Lang Pathol 2016; 18: 483-492.

40. Kumin L. Speech intelligibility and childhood verbal apraxia in children with Down syndrome. Down Syndr Res Pract 2006; 10: 10-22.

41. Regis MS, Lima ILB, Almeida LNA, Alves GÂDS Delgado IC. Speech-language therapy stimulation in children with Down's syndrome. Rev CEFAC 2018; 20: 271-280.

42. Caselli MC, Vicari S, Longobardi E, Lami L, Pizzoli C, Stella G. Gestures and words in early development of children with Down syndrome. J Speech Lang Hear Res 1998; 41: 1125-1135.

43. Stoel-Gammon C. Down syndrome phonology: developmental patterns and intervention strategies. Downs Syndr Res Pract 2001; 7: 93-100.

44. Lynch MP, Oller DK, Steffens ML, Buder EH. Phrasing in prelinguistic vocalizations. Dev Psychobiol 1995; 28: 3-25.

45. Paterson S. Language and number in Down syndrome: the complex developmental trajectory from infancy to adulthood. Down Syndr Res Pract 2001; 7: 79-86.

46. Laws G, Bishop DVM. Verbal deficits in Down's syndrome and specific language impairment: a comparison. Int J Lang Commun Disord 2004; 39: 423-451.

47. Wishart JG. Socio-cognitive understanding: a strength or weakness in Down's syndrome? J Intellect Disabil Res 2007; 51( Pt 12): 996-1005.

48. Rosner BA, Hodapp RM, Fidler DJ, Sagun JN, Dykens EM. Social competence in persons with Prader-Willi, Williams and Down's syndromes. J Appl Res Intellect Disabil 2004; 17: 209-217.
49. Næss KB, Nygaard E, Ostad J, Dolva AS, Lyster SH The profile of social functioning in children with Down syndrome. Disabil Rehabil 2017; 39: 13201331.

50. Jahromi LB, Gulsrud A, Kasari C. Emotional competence in children with down syndrome: negativity and regulation. Am J Ment Retard 2008; 113: 32-43.

51. Cicchetti D, Sroufe LA. The relationship between affective and cognitive development in Down's syndrome infants. Child Dev 1976; 47: 920-929.

52. Pochon R, Touchet C, Ibernon L. Emotion recognition in adolescents with Down syndrome: a nonverbal approach. Brain Sci 2017; 7: 55.

53. Kasari C, Freeman SF, Hughes MA. Emotion recognition by children with Down syndrome. Am J Ment Retard 2001; 106: 59-72.

54. Williams KR, Wishart JG, Pitcairn TK, Willis DS. Emotion recognition by children with Down syndrome: investigation of specific impairments and error patterns. Am J Ment Retard 2005; 110: 378-392.

55. Ghaziuddin M, Tsai LY, Ghaziuddin N. Autism in Down's-syndrome - presentation and diagnosis. J Intellect Disabil Res 1992; 36(Pt 5): 449-456.

56. Moss J, Richards C, Nelson L, Oliver C. Prevalence of autism spectrum disorder symptomatology and related behavioural characteristics in individuals with Down syndrome. Autism 2013; 17: 390-404.

57. Warner G, Howlin P, Salomone E, Moss J, Charman T. Profiles of children with Down syndrome who meet screening criteria for autism spectrum disorder (ASD): a comparison with children diagnosed with ASD attending specialist schools. J Intellect Disabil Res 2017; 61: 75-82.

58. Reilly C. Autism spectrum disorders in Down syndrome: a review. Res Autism Spectr Disord 2009; 3: 829-839.

59. DiGuiseppi C, Hepburn S, Davis JM, et al. Screening for autism spectrum disorders in children with Down syndrome: population prevalence and screening test characteristics. J Dev Behav Pediatr 2010; 31: 181-191.

60. Hepburn S, Philofsky A, Fidler DJ, Rogers S. Autism symptoms in toddlers with Down syndrome: a descriptive study. J Appl Res Intellect Disabil 2008; 21: 48-57.

61. Filipek PA, Accardo PJ, Ashwal S, et al. Practice parameter: screening and diagnosis of autism: report of the Quality Standards Subcommittee of the American Academy of Neurology and the Child Neurology Society. Neurology 2000; 55: 468-479. 
62. Capone GT, Grados MA, Kaufmann WE, BernadRipoll S, Jewell A. Down syndrome and comorbid autism-spectrum disorder: characterization using the aberrant behavior checklist. Am J Med Genet A 2005; 134: 373-380.

63. Coe DA, Matson JL, Russell DW, et al. Behavior problems of children with Down syndrome and life events. J Autism Dev Disord 1999; 29: 149-156.

64. Cuskelly M, Dadds M. Behavioural problems in children with Down's syndrome and their siblings. J Child Psychol Psyc 1992; 33: 749-761.

65. Will EA, Gerlach-McDonald B, Fidler DJ, Daunhauer LA. Impact of maladaptive behavior on school function in Down syndrome Res Dev Disabil 2016; 59: 328-337.

66. Gath A, Gumley D. Behaviour problems in retarded children with special reference to Down's syndrome. Br J Psychiatry 1986; 149: 156-161.

67. Oxelgren UW, Myrelid A, Annerén G, et al. Prevalence of autism and attention-deficithyperactivity disorder in Down syndrome: a population-based study. Dev Med Child Neurol 2017; 59: 276-283.

68. Hernández Martínez M, Pastor Duran X, Navarro Navarro J. Attention deficit disorder with or without hyperactivity or impulsivity in children with Down's syndrome. Rev Med Int Sindr Down 2011; 15: 18-22.

69. Pueschel SM, Bernier JC, Pezzulo JC. Behavioural observations in children with Down's syndrome. J Ment Defic Res 1991; 35(Pt 6): 502-511.

70. Palumbo ML, McDougle CJ. Pharmacotherapy of Down syndrome. Expert Opin Pharmacother 2018; 19: $1875-1889$.

71. Hernandez D, Fisher EM. Down syndrome genetics: unravelling a multifactorial disorder. Hum Mol Genet 1996; 5: 1411-1416.

72. Hodapp RM, Evans DW, Gray FL. Intellectual Development in Children with Down Syndrome. In: Rondal J, Perera J, Nadel L (eds). Down syndrome: a review of current knowledge. London: Whurr, 1999: 124-132.

73. Daunhauer LA, Gerlach-McDonald B, Will E, Fidler DJ. Performance and ratings based measures of executive function in school-aged children with Down syndrome. Dev Neuropsychol 2017; 42: 351368.

74. Raitano Lee N, Pennington BF, Keenan JM. Verbal short-term memory deficits in Down syndrome: phonological, semantic, or both? J Neurodev Disord 2010; 2: 9-25.

75. Rowe J, Lavender A, Turk V. Cognitive executive function in Down's syndrome. Br J Clin Psychol 2006; 45(Pt 1): 5-17 .
76. Fidler DJ, Nadel L. Education in children with Down syndrome: neuroscience, development, and intervention. Ment Retard Dev Disabil Res Rev 2007; 13: $262-271$.

77. Daunhauer LA, Fidler DJ. The Down syndrome behavioral phenotype: implications for practice and research in occupational therapy. Occup Ther Health Care 2011; 25: 7-25.

78. Chapman RS, Hesketh LJ. Language, cognition, and short-term memory in individuals with Down syndrome. Down Syndr Res Pract 2001; 7: 1-7.

79. Agheana V, Duță N. Achievements of numeracy abilities to children with Down syndrome: psychopedagogical implications. Procedia Soc Behav Sci 2015; 186: 38-45.

80. Boudreau D. Literacy skills in children and adolescents with Down syndrome. Read Writ An Interdiscip J 2002; 15: 497-525.

81. Laws G, Byrne A, Buckley S. Language and memory development in children with Down syndrome at mainstream schools and special schools: a comparison. Educ Psychol 2000; 20: 447-457.

82. Lanfranchi S, Jerman O, Vianello R. Working memory and cognitive skills in individuals with Down syndrome. Child Neuropsychol 2009; 15: 397416.

83. Will E, Fidler DJ, Daunhauer L, Gerlach-McDonald B. Executive function and academic achievement in primary-grade students with Down syndrome. J Intellect Disabil Res 2017; 61: 181-195.

84. Turner S, Alborz A, Gayle V. Predictors of academic attainments of young people with Down's syndrome. J Intellect Disabil Res 2008; 52(Pt 5): 380-392.

85. Fidler DJ, Most DE,Booth-LaForce C, Kelly JF. Emerging social strengths in young children with Down syndrome. Infants Young Child 2008; 21: 207220.

86. Germain R. A 'positive' approach to supporting a pupil with Down syndrome during 'dedicated numeracy time’? Down Syndr Res Pract 2002; 8: 5358.

87. Landry SH, Miller-Loncar CL, Swank PR. Goaldirected behavior in children with Down syndrome: the role of joint play situations. Early Educ Dev 1998; 9: 375-392.

88. Colozzo P, McKeil L, Petersen JM, Szabo A. An early literacy program for young children with Down syndrome: changes observed over one year. J Policy Pract Intellect Disabil 2016; 13: 102-110.

89. Buckley S, Bird G, Sacks B. Evidence that we can change the profile from a study of inclusive education. Down Syndr Res Pract 2006; 9: 51-53. 